\title{
EUSEBIO LUCINI, ESCENÓGRAFO DE LOS BALLETS REPRESENTADOS EN EL TEATRO DEL CIRCO DE MADRID EN LA DÉCADA DE $1840^{*}$
}

\author{
LAURA HORMIGÓN ${ }^{1}$ \\ Universidad Complutense de Madrid / Revista ADE-Teatro
}

\begin{abstract}
Durante la década de 1840, Eusebio Lucini desempeñó una labor fundamental como escenógrafo y director de maquinaria del Teatro del Circo de Madrid, donde realizó las escenografías de los ballets y óperas que se representaron allí. Por desgracia, de su trabajo escenográfico no ha sobrevivido nada - a excepción de pequeños grabados publicados en la prensa-, y lo poco que sabemos de sus decorados es gracias a las descripciones publicadas en la prensa de la época. Este recorrido por la poco estudiada producción escenográfica para ballet desarrollada por Lucini pretende visibilizar y poner en valor su gran actividad artística, además de constatar que, el Teatro del Circo realizó, en aquel momento, una programación de ballet equivalente a la de los teatros más importantes de Europa, también en cuanto a sus producciones escenográficas.
\end{abstract}

Palabras clave: Eusebio Lucini; escenografía para ballet; escenografía España siglo XIX; Teatro del Circo de Madrid; ballet romántico; Marius Petipa.

\section{EUSEBIO LUCINI, STAGE DESIGNER OF THE BALLETS PERFORMED AT THE CIRCO THEATRE OF MADRID IN THE 1840S}

During the 1840s, Eusebio Lucini played an outstanding role as set designer and machinery director at the Circo Theatre in Madrid, where he created the sets for the ballets and operas performed there. Unfortunately, none of his sets has survived, with the exception of small engravings published in the press. The little that we know of his works is thanks to the descriptions published in the press of the time. This journey around the little known ballet's production developed by Lucini, aims to make visible and value his great artistic activity, in addition to verifying that the Circo Theatre programmed, in that moment, the same ballet repertoire as the most important theatres in Europe, also in terms of stage productions.

Key words: Eusebio Lucini; ballet scenography; scenography in Spain XIX century; Circo Theatre of Madrid; romantic ballet; Marius Petipa.

Cómo citar este artículo / Citation: Hormigón, Laura (2020) "Eusebio Lucini, escenógrafo de los ballets representados en el Teatro del Circo de Madrid en la década de 1840". En: Archivo Español de Arte, vol. 93, núm. 372, Madrid, pp. 375-390. https://doi.org/10.3989/aearte.2020.25

En los ballets románticos, la escenografía, el vestuario y la iluminación tuvieron un papel fundamental. Tanto los elementos de la puesta en escena como la música y la coreografía debían contribuir a crear un determinado sentido "de lugar", y se esperaba que recrearan con propiedad,

\footnotetext{
* Este artículo se enmarca en el proyecto de investigación P. E. I+D+i Tras los pasos de la Sílfide. Una historia de la daza en España, 1836-1936 (ref. PGC2018 093710 A I00), financiado por (MCIU/AEI/FEDER, UE).

1 lhormigonv@gmail.com / ORCID iD: https://orcid.org/0000-0002-8974-7084
} 
autenticidad y realismo los espacios en los que iban a desarrollarse cada una de las escenas de un ballet.

El público de mediados del siglo XIX fue demandando cada vez mayor espectacularidad en el ejercicio teatral y esta ostentación escenográfica y decorativa se manifestó, por ejemplo, a través de la representación de lugares grandiosos y fascinantes, mutaciones sorpresivas y complejos cambios de escenas. Se reconstruían ambientes que destacaban por su exotismo, su pintoresquismo o su veracidad histórica² ${ }^{2}$.

Sabemos de la opulencia con la que solían escenificarse las representaciones líricas y los ballets en la Ópera de París, hasta el punto de que la grandiosidad de los decorados se convirtió en un requisito necesario para el éxito de un espectáculo. Aunque no hay que olvidar que, por ser la llamada "pintura de escena" la parte de la producción que con frecuencia recibía menos presupuesto, la reutilización y adaptación tanto de vestuario como de decorados procedentes de otras obras se mantuvo como una constante en el ejercicio teatral decimonónico, incluso en los mayores teatros de Europa ${ }^{3}$. Los telones se repintaban y restauraban para obras nuevas hasta que verdaderamente se deshacían de viejos. Por esta razón se le daba tanta importancia al estreno de alguna "decoración" en una representación, acontecimiento que, por supuesto, recogía la prensa y servía de aliciente para el público.

Complemento indispensable de los telones era el sistema de alumbrado del escenario, para el que se utilizaba un sistema de ringlas de luces en el telar y en los varales, colocados en distintos puntos del escenario. Éstos daban una luz difusa que favorecía la libertad de la pintura del escenógrafo. Para iluminar de otra manera habría sido necesario eliminar las bambalinas y los bastidores. Cuando en una escena era necesario que el personaje jugara con el reflejo de su propia sombra — como en el Paso de la sombra de la Ondina —, se utilizaba la lámpara Drummond ${ }^{4}$. La iluminación con gas aplicada al teatro no se introdujo en Madrid hasta 1848, precisamente en el Teatro del Circo 5 .

\section{Algunas características generales de la escenografía decimonónica española}

Durante la primera etapa del romanticismo español perduró el neoclasicismo, debido sobre todo a la aportación de varios escenógrafos italianos. Para Navascués, estos pintores de escena fueron "el soporte más firme de nuestra escenografía, comenzando por la labor desarrollada por los hermanos Tadey" XVIII y hasta la época de Fernando VII. También hay que destacar a la familia Lucini -Francesco, Giuseppe y Eusebio - afincada primero en Barcelona y luego en Madrid, quienes influyeron en la pintura de escena realizada por los escenógrafos españoles. Cabe recordar asimismo a Bernardo Bonardi, Giorgio Bussato y Augusto Ferri. Este último, parece que "introdujo la luz y el color que faltaban en Lucini" mostrándose "más atento al vitalismo de la escenografía que a su exacta construcción. Ferri incorporó el lirismo romántico y expresivo"?.

Posteriormente la influencia vino de escenógrafos franceses como Edouard Despléchin, Pierre Charles Cicéri y sus discípulos: Charles A. Cambón y Fèlix Cagé. Según Nieva, estos

\footnotetext{
${ }^{2}$ Más sobre escenografía y maquinaria teatral del siglo XIX en Arregui, 2009. Sobre arquitectura teatral, escenografía, maquinaria e iluminación en la segunda mitad del siglo XIX en Moynet, 1999. Sobre escenografía y escenógrafos en España en Muñoz Morillejo, 1923; Arias de Cossío, 1991; Arregui, 2009; Navascués, 1984.

3 Smith, 2000: 51, señala el número de trajes originales y aquellos que fueron adaptados para los ballets creados en la Ópera de París a mediados del siglo XIX.

${ }^{4}$ Más sobre iluminación teatral en el siglo XIX en Manjarrés, 1875: 172-173; Arregui, 2009.

${ }^{5}$ La primera vez que se utilizó la iluminación con gas en el teatro fue en Londres (1817) y más tarde en París (1822). En España el gas no fue aplicado al teatro hasta 1847, en el Gran Teatro del Liceo, y un año más tarde en Madrid. Hormigón, 2017: 73-74.

6 Navascués, 1984.

7 Navascués, 1984.
} 


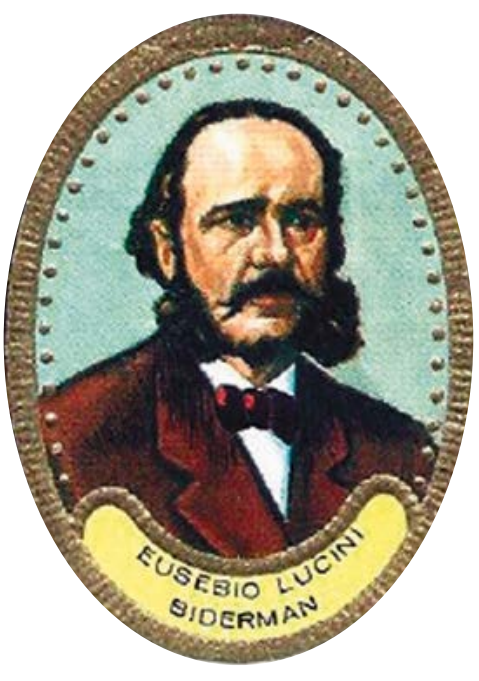

Fig. 1. Retrato de Eusebio Lucini en una vitola de puros. (Col. L. Hormigón). artistas "afirmaron el dominio del escenario pintado, que ofrecía todas las posibilidades descriptivas" que los escenógrafos italianos tuvieron una gran aceptación en Madrid, el que podríamos llamar "grupo francés" se asentó principalmente en Barcelona. Aunque también trabajaron en la capital franceses como Henri Philastre. Por tanto, en la escenografía española del siglo XIX se extendió: “(...) Una manera de hacer común en la que el dominio francés se asentó sobre los fundamentos italianos tradicionales, renovando los modos y la factura de la pintura teatral. Al contrario que en otros lugares, no se consideraron escuelas antagónicas sino que acabaron mezclándose" $"$.

Arias de Cossio ha señalado también que, durante la década de 1840, los escenógrafos que trabajaron en España le otorgaron a la escena un "realismo de carácter geográfico preciso" en el que fueron "incorporando detalles costumbristas o incluso anecdóticos" ${ }^{10}$, que aumentaban el realismo de la escena.

\section{Creaciones de Eusebio Lucini para el Teatro del Circo de Madrid (1842-1848)}

La familia de Eusebio Lucini (Barcelona, 1814-Madrid, 1881) provenía de Reggio Emilia (Italia). Su tío Giuseppe (1770-1845) fue el primero en instalarse en Barcelona y curiosamente se conservan algunos bocetos de sus trabajos escenográficos, algo que lamentablemente no ha ocurrido con los de Eusebio. Francesco (1789-1846), el padre de Eusebio, trabajó desde 1814 en los teatros de Barcelona, Valencia y Madrid, adonde llegó en 1838. Lucini padre e hijo trabajaron en la capital, cada uno en su respectivo teatro, durante toda la década de 1840 .

Entre 1835 y 1837, Eusebio viajó a Italia para completar sus estudios y desde 1840 trabajó en Madrid. Primero pasó dos años en el Teatro de la Cruz y a partir de 1842 fue escenógrafo y director de maquinaria del Teatro del Circo, donde creó los decorados para ballets y óperas. Desde mediados de 1848 compaginó este trabajo con su actividad en el Gran Teatro del Liceo de Barcelona, donde se relacionó con un grupo de importantes escenógrafos franceses como Félix Cagé. En 1850 regresó al Teatro del Circo y entre 1850 y 1856 fue escenógrafo del Teatro Real de Madrid [fig. 1].

En 1842 Lucini diseñó, para el Teatro del Circo, cinco de los seis decorados del ballet en tres actos César en Egipto ${ }^{11}$, puesto en escena por Federico Massini en julio. Un hermoso telón para el ballet cómico en un acto La viuda caprichosa - también escenificado por Massini- que representaba un salón iluminado desde el que se veía un cielo estrellado a lo lejos ${ }^{12}$. Fue tal la acogida de este decorado, que el escenógrafo tuvo que salir al escenario para recibir los aplausos del público.

El último ballet que Lucini realizó ese año fue La Sylphide ${ }^{13}$. Se dio la coincidencia de que la escenografía creada para las dos puestas en escena de La Silfide estrenadas en Madrid, en 1842,

8 Nieva, 2000: 64.

${ }^{9}$ Arregui, 2009: 403-404.

10 Arias de Cossío, 1991: 100.

11 Basado en las escenificaciones de Gaetano Gioja y Giovanni Monticini (Venecia, 1812). Girardi/ Rossi, 1989 : 73. Ballet frecuente en los teatros italianos durante las tres primeras décadas de 1800. Pedro Ronzi realizó el primer decorado del $3^{\text {er }}$ acto.

12 "Teatro del Circo", El Espectador, 31-VII-1842, describe toda la escenografía creada por Lucini para esta escena.

13 Ballet de Filippo Taglioni con música de Jean Schneitzhöffer, estrenado en París en 1832. La historiografía del ballet toma el estreno de este ballet como fecha de inicio del periodo del ballet romántico, que concluye en 1870 con el estreno parisino de Coppelia. 
estuvo a cargo de dos miembros de la familia Lucini. Los decorados del montaje de Victor Bartholomin para el Teatro del Príncipe fueron ejecutados por Francisco, el padre de Eusebio. Mientras que los de la producción del Circo, a cargo de Massini, los realizó el propio Eusebio. Fue muy comentado que en la producción del Teatro del Circo se utilizaran cuatro decorados en lugar de dos, uno por acto, como sucedía en la escenificación original parisina.

Por otra parte, el libreto de Massini indicaba que, al final del ballet, “(...) la escena se transforma en una colina cubierta de flores y a los pies un pequeño lago; y el teatro representa el Olimpo"14. Di Tondo ha explicado que, según la tradición italiana, en la penúltima escena de los ballets solía representarse una "colina cubierta de flores a cuyos pies hay un pequeño lago" 15 . Esta iconografía respondía a las características del locus amoenus (lugar idílico) de la época y, como hemos visto, apareció en La Silfide de Massini representada en Madrid. Otra característica de la producción del Circo era que las bailarinas/ sílfides no volaban, por lo que Soriano Fuertes señaló que, en decorados y trajes "había ganado el Circo" con diferencia, pero "en los vuelos el Príncipe" 16 . Aunque parece que las transformaciones del Circo estuvieron bien ideadas, el crítico de La Posdata consideró que fueron "torpemente ejecutadas", si bien justificaba el error por la "falta de ensayos". Sin embargo señaló que, en la segunda representación, el público quedó más complacido con los efectos de maquinaria y que Lucini "fue llamado a la escena por la decoración del Olimpo" ${ }^{17}$. En mayo de 1845 se repuso este ballet en el Circo, aunque escenificado por Jean Antoine Petipa, padre del gran Marius Petipa, que desde 1844 era primer bailarín del Teatro del $\mathrm{Circo}^{18}$. La prensa anunció entonces que, en el primer acto, se estrenaría un decorado nuevo realizado por Lucini.

En el ballet histórico en tres actos Los griegos o la libertad de Grecia (1843) - escenificado en Madrid por el primer bailarín Emile Rouquet, a partir de la coreografía de A. Blache de 1827- Lucini se encargó de la compleja maquinaria y de los decorados, entre los que destacó el último, que fue considerado admirable.

Ocho fueron los decorados que creó para Los Titanes o las cuatro edades del mundo ${ }^{19}$, ballet que fue estrenado a su beneficio. De la "linda" escenografía destacaron "las figuras de gigantes [que] honran al artista que las ha pintado" 20 . Pero se criticó lo mal iluminado que estuvo el escenario, lo que impidió que la escenografía luciera todo lo que debía.

En octubre del mismo año se estrenaron dos ballets en el teatro. Para el montaje de La Gyp$s y^{21}$ Lucini pintó cinco decorados "excelentes, que agradaron sobremanera"22: "Una vista original de Escocia. Un campamento de gitanos. Gran plaza y puente de Edimburgo. El gabinete de Lord Campbell. Y la cascada y jardines de palacio"23. Su trabajo fue calificado como de "mucha novedad", destacando entre los decorados el de la vista de Edimburgo. Sin embargo, se echó en falta que Lucini no hubiera sido llamado a saludar a la escena, para que el público hubiera podido reconocerle merecidamente su trabajo.

Aunque veremos que, habitualmente, la labor de Lucini era bien recibida, en la puesta en escena madrileña de Giselle ${ }^{24}$ lo más criticado fue su escenografía. A Zampa — seudónimo con el

${ }^{14}$ La Sílfide. Madrid, 1842. Biblioteca Nacional de España (BNE), T/15298.

15 Di Tondo, 2012: 202.

16 Soriano Fuertes: "Variedades", La Iberia Musical y Literaria, 16-X-1842.

17 "Bailes", La Posdata, 12-X-1842.

18 Marius Petipa trabajó en España de junio de 1844 a enero de 1847. Más información sobre la etapa española de Petipa en Hormigón, 2010; 2017; 2018.

19 Puesto en escena por F. Massini a partir del ballet homónimo de Galzerani (Nápoles, 1831). Los Titanes o las cuatro edades del mundo. Madrid, 1843. BNE, T/11333.

20 "Libro de memorias. Teatro del Circo", El Reflejo, 16-III-1843.

${ }_{21}$ Ballet de Joseph Mazilier con música de François Benoist, Ambroise Thomas y Marliani, estrenado en París en 1839.

22 "Revista de Teatros. Gipsy o la gitana", Revista de Teatros, 5-X-1843.

23 "Diversiones Públicas. Teatros. Del Circo", Diario de Avisos de Madrid, 12-XI-1843.

${ }^{24}$ Ballet en dos actos con coreografía de Jean Coralli y música de Adolphe Adam, entrenado en París en 1841. Puesto en escena en Madrid, en 1843, por Achille Henry, con el título de Gisela o las willis. BNE, T/25151. 

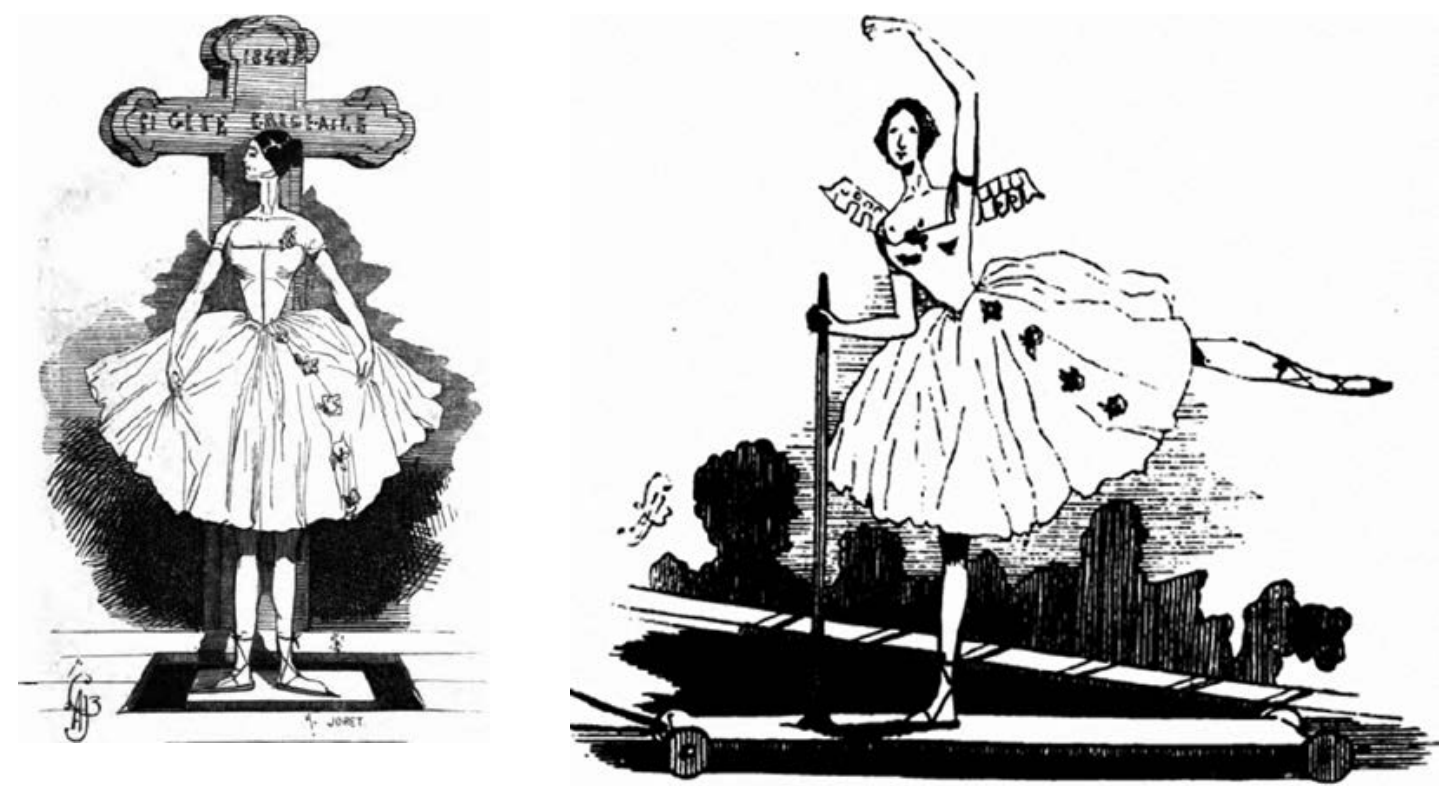

Figs. 2a y 2b. Caricaturas de Lorentz de algunos trucos de maquinaria utilizados en el segundo acto de Giselle. (Musée Philipon, París, nº 9).

que escribía sus reseñas el músico Joaquín Espín y Guillén — los decorados y la maquinaria le parecieron "de teatro casero" y aseguró que, para hacer buenas producciones de ballets, se necesitaba "gastar mucho dinero y tener tramoyistas inteligentes" 25 . Después de estos comentarios, se puede deducir que, posiblemente, no todos los efectos de maquinaria escénica previstos para el segundo acto, en la producción original parisina, fueron utilizados en Madrid. En cambio - $\mathrm{y}$ en contra de lo que afirmaron otros periódicos de la capital - La Posdata consideró que la producción había sido aceptable, augurándole a la empresa "excelentes resultados" 26 con esta obra. Y no se equivocaron, porque Gisela fue el ballet más escenificado en el Teatro del Circo entre 1843 y 1850 , alcanzando unas setenta funciones y estando presente durante seis temporadas ${ }^{27}$.

A medida que fue representándose, la producción, la maquinaria y el vestuario fueron mejorándose: "en las nuevas funciones de Gisela las decoraciones, trajes, maquinaria y aparato escénico han recibido una mejora notable" 28 . Sin embargo, en 1847 , todavía se criticaba que: "(...) ni se ve la luna, ni aparece el lago, ni la escena se presenta (...) tal y como la describen SaintGeorges y Gautier"29 [figs. 2a y 2b].

El ballet en un acto La Aurora ${ }^{30}$ subió a escena en el Teatro del Circo en noviembre de 1843. Esta producción, a pesar de ser considerada por Enrique Gil como "carente de algún género de interés dramático" 31 , se mantuvo en el repertorio del teatro durante varias temporadas. Para el estreno, Lucini pintó un decorado nuevo.

En el ballet fantástico en dos actos El lago de las hadas ${ }^{32}$ - escenificado en Madrid por Giuseppe Villa - fueron tres los decorados que diseñó: un bosque rodeado de árboles silvestres

25 Zampa: "Gysela (sic) o las wilis", La Iberia Musical y Literaria, 29-X-1843.

26 La Posdata, 26-X-1843.

27 Hormigón, 2017: 223

28 "Crónica de Teatros. Teatro del Circo", El Clamor Público, 27-III-1845.

29 "Revista Musical. Teatro del Circo", El Español, 12-V-1847.

${ }^{30}$ L'Aurore, coreografía de Perrot con música de Cesare Pugni, estrenada en Londres ese mismo año.

31 Enrique Gil: "Revista de la quincena", El Laberinto, 1-XII-1843.

32 Le lac des fées, coreografía de Antonio Guerra estrenada en Londres en 1840, a partir de la ópera homónima de Daniel-François Auber con libreto de Eugène Scribe. 
con un profundo lago y algún sendero en medio de la maleza; la plaza pública, a la derecha una casa de labradores, al fondo un palacio con sus almenas; y la transformación del escenario y aparición del interior del lago donde habitan las hadas. El último decorado estaba "perfectamente entendido" 33 y se aconsejó no cerrar tan pronto el telón para que el público disfrutara de esta "fantástica y hermosa" 34 imagen.

En cuanto a la maquinaria, fueron necesarios varios trucos para hacer posibles los efectos previstos en el ballet. Algunos de ellos se indicaban en el propio libreto ${ }^{35}$. Por ejemplo, en el primer acto, la reina de las hadas aparecía en escena "brotando de la espuma como la Venus del poeta" 36 . En este mismo acto se utilizó un efecto de iluminación en el que "la pálida luz de la argentada luna [se] refleja sobre el suelo". Este efecto fue celebrado por la prensa porque, "la luz de la luna estaba muy bien figurada" aunque, si hubiera tenido "un poco más de serenidad en su resplandor" ${ }^{\prime 3}$, todavía se habría logrado más la ilusión.

En febrero de 1844 se estrenó el ballet en tres actos Los ingleses en el Indostán ${ }^{38}$, en una función a beneficio de Lucini. Para esta obra preparó cinco decorados nuevos que fueron considerados lo mejor del ballet, junto con la participación de Marie Guy-Stéphan. Un mes más tarde, cuando se representó el ballet en dos actos La isla del amor ${ }^{39}$, Gil afirmó que el espectáculo "estuvo bien exornado por Lucini, y que la última decoración de la apoteosis, que representa el Templo del Amor, era de muy bello efecto" 40 .

Para el estreno de La hermosa Beatriz ${ }^{41}$, escenificado en julio de 1844 por Jean Baptiste Barrez, Lucini pintó cinco decorados nuevos, de los siete que necesitaba el ballet. El Heraldo escribió que eran "bellísimos. El del salón del $2^{\circ}$ acto era de un efecto nuevo y brillante" 42 . Para la Revista de Teatros la escenografía de Lucini fue "lo mejor que hemos visto en nuestros días"43. Pérez Calvo comentó que, la empresa del teatro había utilizado en esta producción todo lo necesario "en riqueza de trajes y asombrosas y hermosas decoraciones" 44 . Entre los decorados destacaron, por su "efecto singular", "la plaza de Gante del $1^{\text {er }}$ acto; el magnífico, y nunca visto en nuestros teatros, salón de baile en el $2^{\circ}$; y el jardín con grupos de árboles iluminados por innumerables luces en vasos de colores en el $3^{\circ}$ ". Menos satisfecho se mostró otro crítico para quien, ni la escenografía ni la maquinaria del ballet merecían grandes elogios. Consideró que el decorado de la plaza del primer acto "(...) carecía de mérito artístico, tanto en la parte del colorido, como en la de perspectiva. Los efectos de claroscuro adolecen de tanta exageración que los collarines y capiteles de las columnas de la derecha, que se suponen heridos por los rayos del sol occidental, tienen un color de mazarrón de malísimo efecto" "45. Sin embargo, este cronista reconoció que el salón del baile de máscaras del segundo acto "era de muy buen gusto". No obstante, lo que menos le agradó fue que los cambios escenográficos se desempeñaron de una manera un tanto tosca y descuidada, porque los mozos encargados de realizarlos y recolocarlos eran perfectamente visibles, algo impensable "en todos los teatros con alguna fama", donde se disponía de mecanismos o resortes que permitían que estos movimientos pasaran más desapercibidos.

33 "El lago de las hadas", La Posdata. 26-XII-1843.

34 "Revista de la quincena", El Laberinto, 16-I-1844.

35 El lago de las hadas. Madrid, 1843. BNE, T/ 25189.

36 "Boletín de Madrid", El Espectador, 31-XII-1843.

37 "Revista de la quincena", El Laberinto, 16-I-1844.

${ }^{38}$ Dirigido en Madrid por Villa a partir del ballet que él mismo había montado en Turín (1834), Milán (1836) y Trieste (1842-1843).

39 Escenificado por Villa a partir de I viaggiatori all'isola d'amore de A. Monticini (Milán, 1839). En Madrid solo se representó en tres ocasiones.

${ }^{40}$ Enrique Gil: "Revista de la quincena", El Laberinto, 16-III-1844.

41 La jolie fille de Gand, ballet de Albert con música de Adam, estrenado en París en 1842. En Madrid también se conoció como La linda Beatriz.

42 "Teatro del Circo. Primera representación de La linda Beatriz o el sueño", El Heraldo, 11-VII-1844.

43 "Revista de Teatros", Revista de Teatros, 10-VII-1844.

44 Pérez Calvo: "Revista de la quincena", El Laberinto, 15-VII-1844.

45 “Sección Literaria. Teatro del Circo. La linda Beatriz", El Clamor Público, 17-VII-1844. 
En septiembre de 1844 se estrenó en el Circo La tarántula ${ }^{46}$, ballet pantomímico en dos actos puesto también en escena por Barrez. Contó con dos decorados nuevos de Lucini. Encontramos una diferencia importante en la indicación escenográfica para la segunda escena del segundo acto. Mientras que en la producción madrileña se desarrollaba en el mismo decorado que el primer acto, en el libreto original indicaba: "un paisaje montañoso, [y] un convento en primer plano". Es muy posible que la repetición de decorado en Madrid fuera necesaria para abaratar los costes de la producción. Tras el estreno, los decorados fueron calificados como "en general muy pobres y la maquinaria sin novedad ni atractivo" 47 , mientras que para otro crítico, sencillamente no se había utilizado aparato escénico ${ }^{48}$. Pérez Calvo lo consideró un ballet "falto de argumento, pobre en decoraciones y escaso de bailables" 49 .

Durante 1844 debemos destacar, especialmente, la imponente escenografía que Lucini creó para $L a$ Péri ${ }^{50}$, ballet fantástico en dos actos ambientado en Oriente, puesto en escena en Madrid por Barrez. Los decorados, además de espectaculares, debieron ser muy laboriosos en cuanto a su montaje porque la prensa, antes del estreno, iba preparando al público informándole de que uno de los descansos duraría casi una hora y que, para hacerlo más llevadero, la orquesta tocaría una sinfonía nueva de Skoczdopole ${ }^{51}$. También existió otro momento de transición escenográfica, al comienzo del segundo cuadro del segundo acto, en el que el escenario permanecía sin acción algunos minutos, durante los cuales la orquesta seguiría tocando. Precisamente uno de los aspectos más criticados del ballet fue lo largo de los descansos - consecuencia de la complejidad de los cambios escenográficos, algunos corpóreos-, que disgustaron mucho a los espectadores, a pesar de que la espera estuvo amenizada con música.

Un crítico consideró tras el estreno que el ballet gustaría más cuando se hubiera repetido varias veces, "porque es demasiado complicado y adoleció el primer día de falta de ensayos" 52 . Pérez Calvo destacó especialmente el mérito del último decorado del ballet, porque era asombroso $^{53}$. Y Ramón de Navarrete aseguró que los decorados de Lucini eran “(...) ricos y costosos. Magníficos y dignos de los mayores elogios. Ellos solos bastan para asegurar su éxito. La vista de El Cairo desde la azotea de Achmet, y el último, se distinguen entre todos por su efecto. (...) la mansión encantada de las péris vino a arrancarle [al público] prolongados aplausos" 54 . Incluso un diario se atrevió a afirmar, de manera algo exagerada, que la escenificación madrileña de este ballet estaba "decorada con un lujo sorprendente que aventaja al aparato con que este espectáculo se estrenó en París" 55.

El diablo enamorado — ballet en tres actos de Joseph Mazilier estrenado en París en 1840-, fue escenificado por Barrez en enero de 1845, "con un lujo deslumbrador" ${ }^{\text {". }}$. El libreto ${ }^{57}$ de Madrid señalaba los diferentes espacios donde transcurría cada acción: un jardín con un quiosco; una antigua biblioteca con su chimenea, situada en el torreón de un castillo gótico; un Palacio; una casita y una parroquia (capilla) ${ }^{58}$ situadas en un promontorio al borde del mar; el bazar de Ispahán y el infierno.

46 La Tarentule, coreografía de Coralli con música de Casimir Gide, estrenado en Paris en 1839.

47 "Sección Literaria. Teatro del Circo", El Clamor Público, 10-IX-1844.

48 "Revista de Teatros", Revista de Teatros, 8-IX-1844.

49 Pérez Calvo: "Revista de la quincena", El Laberinto, 16-IX-1844.

${ }^{50}$ Coreografía de Coralli, música de Friedrich Burgmüller y libreto de Gautier. Estrenado en París en 1843. Fue uno de los grandes ballets románticos sin embargo, en Madrid, no logró igualar el éxito obtenido en Londres o París.

51 Johan Daniel Skoczdopole (1811-1877) fue director de la orquesta del teatro durante varias temporadas. También compuso varios ballets y danzas. A partir de 1850 trabajó en el Teatro Real de Madrid. Hormigón, 2017.

52 "Revista de la semana", La Crónica, 17-XI-1844.

53 Pérez Calvo: "Revista de la quincena", El Laberinto, 15-XI-1844.

54 Ramón de Navarrete: "Gacetilla de la capital”, El Heraldo, 16-XI-1844.

55 "Revista Nacional", La Posdata, 13-XI-1844.

${ }^{56}$ González d'Apoussa: "Crónica Teatral. El diablo enamorado", Eco del Comercio, 6-II-1845.

57 El diablo enamorado. Madrid, 1845. BNE, T/20044.

${ }^{58}$ El original indicaba "una cabaña de pescador sobre la cima de una roca, en la que estaban talladas anchas gradas, y había una capilla que se abría de frente". 


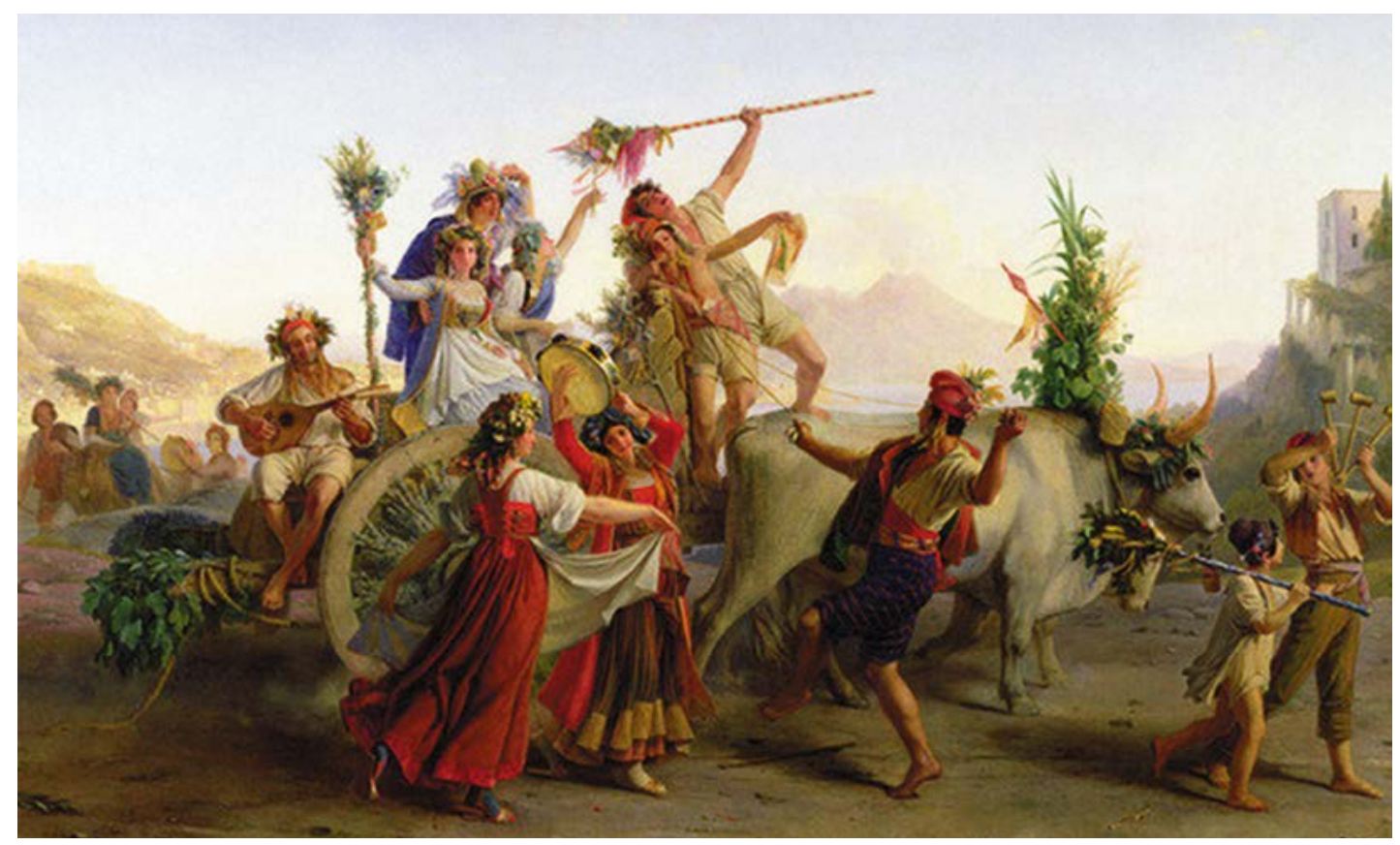

Fig. 3. Regreso del festival de la Madonna dell'Arco de Léopold Robert, ca. 1827. (Museo del Louvre).

La escena de la biblioteca del primer acto se desarrollaba a la luz de la luna, elemento presente en muchos ballets románticos, que incluso apareció dibujado en el figurín original que realizó Lormier para el personaje de Belcebú, y que se conserva en la Biblioteca Nacional de Francia ${ }^{59}$. En esta escena se utilizó la chimenea para que apareciera por ella el diablo acompañado de Uriela. Este mismo recurso escenográfico ya se había utilizado en La Sylphide para hacer desaparecer por ella a la sílfide. En El diablo enamorado también se utilizaron otros elementos de maquinaria escénica habituales durante esta época como truenos, rayos, fuego, paredes que se abrían para que desaparecieran personajes, etc.

Los decorados fueron calificados como "magníficos y bien entendidos"60 y el crítico González d'Apoussa opinó que Lucini era "digno de todo encomio, tanto por sus bellas decoraciones como por lo bien combinado de la maquinaria" ${ }^{61}$. Otro diario también reconoció la belleza de sus decorados y comentó que eran "de lo más lindo que hemos visto en su género y la maquinaria, (...) estuvo perfectamente entendida y ejecutada"62.

Jean Antoine Petipa se encargó de poner en escena La Ondina ${ }^{63}$, en julio de 1845. Para esta ocasión Lucini preparó cuatro magníficos decorados por los que fue llamado a saludar a la escena, para recibir los merecidos aplausos del público. La prensa señaló que, para la $1^{\mathrm{a}}$ escena del $2^{\circ}$ acto, en la que tenía lugar la fiesta de la Madonna, la empresa "creyó conveniente" ${ }^{64}$ representar al natural el cuadro homónimo de Léopold Robert [fig. 3], y en el que se inspiró el propio Jules Perrot para crear esta escena a modo de tableau vivant, utilizando a todo el cuerpo de baile tocando castañuelas y panderetas. Observamos, por tanto, que esta escena se conservó en la puesta en escena madrileña.

${ }^{59}$ Le diable amoureux. Douze maquettes de costumes par Paul Lormier. París, 1840. (BNF) D216-13 (31-42).

${ }^{60}$ Revista de Teatros, 30-I-1845.

${ }^{61}$ González d'Apoussa: “Crónica Teatral. El diablo enamorado”, Eco del Comercio, 6-II-1845.

62 "Revista de la quincena", El Laberinto, 1-II-1845.

63 Ondine ou la náyade, coreografía de Perrot con música de Pugni, estrenado en Londres en 1843, protagonizado por Fanny Cerrito, Guy-Stéphan y el propio Perrot.

64 "Gacetilla de Madrid", El Tiempo, 31-VII-1845. 
También se comentó que, tanto los decorados como la maquinaria escénica, estuvieron perfectamente dirigidos y combinados. La nueva escenografía fue muy celebrada y calificada de bellísima, magnífica y excelente, especialmente el último decorado, que representaba el palacio donde viven las ondinas, que "causó un efecto sorprendente" 65 , porque era admirable, "de mucho efecto y bien ideado"66. Para otro diario, "la vistosa perspectiva que presenta, causó gran impresión en todo el público" "67. Según afirmó Vélaz de Medrano, no se había visto nunca en Madrid mejor efecto que el de este palacio ${ }^{68}$, decorado que, para El Heraldo, era "digno de cualquier gran teatro de Europa", porque era "uno de los mejores que se han visto en Madrid" 69 . Además se señaló que "la diversidad de objetos y trasparentes produjo en la imaginación de los espectadores un entusiasmo inexplicable y un aplauso general que resonaba por todo el teatro" 70 . Incluso en un periódico inglés se publicó un comentario sobre el estreno madrileño de La Ondina en donde señalaron, precisamente, que "los decorados fueron admirables"71.

La Esmeralda ${ }^{72}$ se escenificó en noviembre de 1845 por J. A. Petipa, que interpretó además el personaje de Quasimodo. El libreto ${ }^{73}$ de Madrid ofrecía indicaciones escenográficas que permiten constatar pequeñas divergencias respecto a los decorados previstos para la versión original londinense, y que solo pretendían reducir costes en esta costosa producción: Plaza pública; entrada a la corte de los milagros al anochecer. Cuarto en un antiguo claustro habitado por Esmeralda $^{74}$. Jardín adornado para una fiesta en el palacio de Gandelaurier. Casa pobre ${ }^{75}$. Y vista de la catedral de París; a un lado la entrada a una prisión ${ }^{76}$.

Los decorados realizados por Lucini fueron muy celebrados por Velaz de Medrano ${ }^{77}$ y por $\mathrm{El}$ Heraldo $^{78}$, donde se destacó su mérito y su belleza. Más crítico se mostró otro cronista, que puso objeciones concretas a la ejecución técnica de la escenografía, en especial a la realización de la vista de París del final del ballet:

[La escenografía] hubiera podido ser mejor, porque el decorado del $2^{\circ}$ acto tiene un colorido extravagante y los pabellones del fondo están incorrectamente delineados. Las bambalinas de aire cortan las líneas de los edificios por no haberles dado el pintor proporciones arregladas, y las torres gemelas de la catedral son mezquinas, así como exagerados los botareles. Las nubes que asoman en el fondo por encima de Nuestra Señora parecen cualquier cosa menos nubes iluminadas por la luna ${ }^{79}$.

En marzo de 1846, J. A. Petipa coreografió el ballet fantástico en tres actos, Farfarella o la hija del infierno, para ser estrenado especialmente en el Teatro del Circo de Madrid. La función fue a beneficio de Lucini, que preparó seis decorados nuevos, lo cual demuestra un gasto económico excepcional por parte de la empresa, gestionada entonces por José de Salamanca ${ }^{80}$, hecho que no pasó desapercibido a los cronistas, y por el que felicitaron al empresario.

5 "Gacetilla de Madrid", El Tiempo, 31-VII-1845.

66 "Revista Teatral y Literaria", El Laberinto, 4-VIII-1845.

67 Tío Pacorro y Pacorriyo: "Folletín. La Ondina", Diario de Avisos de Madrid, 3-VIII-1845.

68 Vélaz de Medrano: "Folletín. Teatro del Circo. La Ondina", El Español, 21-IX-1845.

69 "Revista crítica del mes. Folletín", El Heraldo, 3-VIII-1845.

70 Tío Pacorro y Pacorriyo: "Folletín. La Ondina", Diario de Avisos de Madrid, 3-VIII-1845.

71 "A Madonna at the Theatre of Madrid", The Era, Londres, 17-VIII-1845.

72 Coreografía de Perrot con música de Pugni estrenada en Londres en 1844. Se basó en la novela Notre-Dame de Paris de Victor Hugo.

73 La Esmeralda. Madrid, 1845. BNE, T/25166.

${ }^{74}$ El original señalaba "una pequeña cámara abovedada con un pequeño sofá, una mesa y una silla", sin especificar si la habitación se encontraba en un claustro.

75 Así se evitó construir el decorado de "una ventana abierta sobre el río", como indicaba el original.

76 No se situó la escena "a orillas del Sena", como sucedía en la versión inglesa original.

77 Vélaz de Medrano: "Revista Musical”, El Español, 23-XI-1845.

78 "Gacetilla", El Heraldo, 20-XI-1845.

79 "Revista Teatral", El Español, 24-XI-1845.

${ }^{80}$ Salamanca fue empresario del teatro de 1844 a 1848. Más detalles sobre su gestión en Hormigón, 2017: 105-111. 


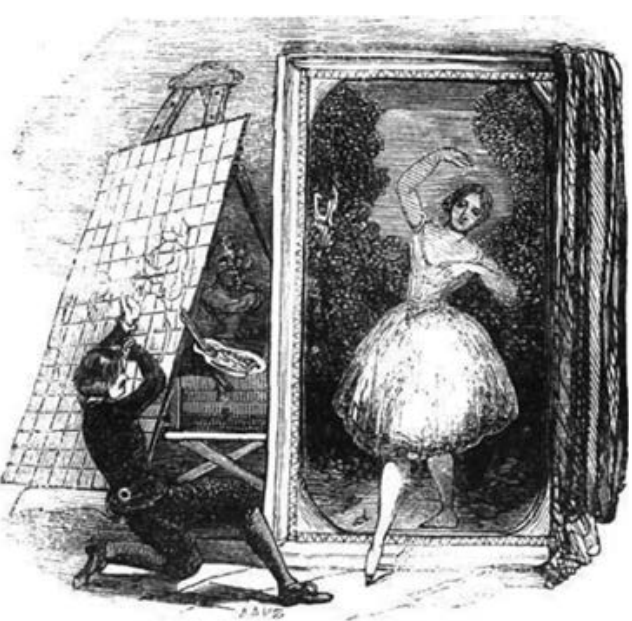

Fig. 4. Marius Petipa y Guy-Stéphan en la escena de El delirio de un pintor del segundo acto de Farfarella. (Semanario Pintoresco Español, 13-IX-1846).

La escenografía debió de ser bastante espectacular y convincente por la unanimidad de opiniones positivas que se publicaron sobre ella, aunque un periódico se lamentó de que los decorados "no hicieron tanto [efecto] como debieron porque los tramoyistas anduvieron un tanto torpes" 81 la primera noche. La magnífica escenografía ayudó a potenciar el éxito del ballet y el día del estreno Lucini tuvo que salir a saludar tras aparecer el decorado del pabellón chino del tercer acto, que era "de un mérito extraordinario" 82 . Los decorados fueron calificados como lindísimos, bien entendidos, de mucho gusto, brillantes $\mathrm{y}$ varios cronistas reconocieron tanto el lujo en el aparato escénico del ballet como el mérito de las creaciones de Lucini, afirmando que eran "dignas de todo elogio por su invención y su colorido" "83. Además se consideró que, con el diseño del estudio del pintor [fig. 4] Lucini había dado "una prueba relevante de sus conocimientos en el arte y de su excelente gusto", porque había creado un decorado soberbio que estaba "hábilmente representado" 84 . Incluso el corresponsal de Teatri, Arti e Letteratura reseñó que Farfarella era un "ballet de grandísimo efecto espléndidamente decorado" 85 .

En este ballet se utilizaron también bastantes efectos de maquinaria escénica, como la aparición entre humo y llamas de Farfarella quien, tras recibir las órdenes de Satán, desaparecía por los aires acompañada de Sataniel. Otro efecto aparecía en el $2^{\circ}$ acto, cuando Farfarella entraba en el estudio del pintor y bajaba suavemente por una ventana. Un recurso muy parecido se empleó en el primer acto de La Sylphide, cuando la protagonista descendía con elegancia por una ventana. Gracias a la reseña de Velaz de Medrano conocemos otros efectos o trucos de maquinaria, como el empleo de aparente fuego real en el infierno del primer acto o que, en el $3^{\text {er }}$ acto, Sataniel salía de escena atravesando una roca ${ }^{86}$.

En noviembre de 1846 - después del retraso provocado tanto por la grave enfermedad sufrida por Lucini, como por una caída de Guy-Stéphan ${ }^{87}$ - Pierre Massot, primer bailarín del teatro, estrenó su ballet en tres actos La Fortuna o la reina del mundo. Para esta obra, el escenógrafo pintó siete decorados nuevos en los que, una vez más, pudo lucir sus conocimientos sobre pintura teatral, y por los que fue aplaudido con entusiasmo. Diseñó: "una tienda de campaña; jardín asiático; selva encantada en la que bailan los genios de la fortuna; salón de baile lujosamente iluminado; gabinete particular, ruinas y la vista exterior de un molino al amanecer" ${ }^{\text {" }}$. La escenografía fue calificada como "verdaderamente magnífica y lo más notable del ballet" ${ }^{89}$. Manuel de Santa Ana escribió al respecto:

Lucini es quien puede vanagloriarse con más razón que ninguno del buen éxito de La Fortuna o la reina del mundo. A su pincel y a su talento se debe que este baile haya hecho un efecto sorprendente. La gloria de la noche, ya que es fuerza decirlo y repetirlo, pertenece a Lucini.

\footnotetext{
81 "Gacetilla de la capital", El Heraldo, 11-III-1846.

82 "Crónica teatral", El Espectador, 6-III-1846.

83 "La Escena, semanario de teatros y costumbres", El Universal, 10-III-1846.

84 "Gacetilla de la capital", El Heraldo, 5-III-1846; "Revista del mes de marzo", El Siglo Pintoresco, 1846.

85 "Teatri. Madrid", Teatri, Arti e Letteratura, Bolonia, 9-IV-1846.

${ }^{86}$ Vélaz de Medrano: "Folletín. Revista coreográfico musical. Teatro del Circo", El Español, 10-III-1846.

87 "Gacetilla de Madrid", El Tiempo, 17-XI-1846.

88 "Gacetilla de la capital", El Heraldo, 12-XI-1846.

89 "Gacetilla de la capital", El Heraldo, 26-XI-1846.
} 
Siete son los decorados nuevos que ha pintado para este ballet y todos le hacen merecedor de un puesto distinguido en su arte. Como lo manifiesta el público llamándole con estrepitosos aplausos a la escena ${ }^{90}$.

En marzo de 1847 se estrenó en el Teatro del Circo el último ballet a cargo de J. A. Petipa, Alba Flor la pesarosa, coreografía en cuatro actos ambientada en la España de Felipe IV. La escenografía fue atribuida a Lucini, aunque parece que no se presentó ningún decorado nuevo, por lo que Fernández de los Ríos los calificó en esta ocasión como "poco notables"91.

Según reflejó la prensa, en mayo del mismo año, Lucini fue llamado por la reina Isabel II a Aranjuez, donde se había trasladado la corte, para que creara nuevos decorados para el teatro, aunque este se encontraba en bastante mal estado. La reina quería que, durante su estancia allí, se presentaran óperas, bailes y dramas.

En junio, Lucini se encargó de la bellísima escenografía de El Corsario, ballet puesto en escena por Auguste Lefebvre, sustituto de J. A. Petipa como maestro de baile del teatro. Lo más celebrado del ballet fueron los decorados y la maquinaria de Lucini, que obtuvo un grandísimo éxito. Se aseguró que "el triunfo del ballet se debía más a Lucini que a Lefebvre" 92 y se consideró que todos los elogios que se dijeran sobre la escenografía no serían suficientes:

La $1^{\mathrm{a}}$ escena, con la vista de una isla en el mar Egeo, era un precioso cuadro lleno de verdad y de vida, cuya ilusión se completaba con la imagen de las dos corbetas ancladas en el puerto. La estancia árabe del $2^{\circ}$ acto estaba pintada con una delicadeza admirable y la lámpara que aparecía colgada sobre el techo del gabinete del bajá producía un efecto maravilloso. También destacó el telón de la escena de la prisión y el mar y el puerto de Corón, que es una verdadera maravilla teatral, especialmente si se tiene en cuenta la pequeñez del escenario y la complicación de la maquinaria ${ }^{93}$.

La escena del combate naval del tercer acto fue una de las partes más celebradas del ballet y se destacó la cuidada elaboración del decorado y la dificultad de la maquinaria, que incluía disparos "reales" de cañones. Para Velaz de Medrano esta batalla era de lo mejor que se había visto en Madrid. Sin embargo, aprovechó para recordarle al escenógrafo que debía "desterrar el actual sistema de bambalinas porque, si corregía algunas ligeras imperfecciones, sus decorados ganarán mucho"94. Fernández de los Ríos afirmó que este combate era "el primer espectáculo de este género que se presentaba en un teatro de Madrid al nivel de los adelantos que la maquinaria ofrece en los del extranjero" 95 [fig. 5].

Existe además una curiosa anécdota sobre los cañonazos de este combate naval. Pocos días después del estreno, habían causado gran sobresalto algunas descargas de cañones que se habían oído, por las calles del centro de Madrid, a horas bastante avanzadas de la noche. Esto hizo creer a algunas personas que se estaba preparando una sublevación. Ante la alarma de la población, la prensa pidió sosiego y explicó que, debido al calor de la estación, las ventanas del Teatro del Circo se dejan abiertas y, con el silencio de la noche, "se perciben perfectamente los tiros con que termina el ballet El Corsario. (...) Todo se reduce a un poco de pólvora" ${ }^{96}$.

Durante 1847 Lucini trabajó en otros tres ballets de Lefebvre. El primero fue Cloris en la corte de Diana, ballet mitológico en dos actos — más del gusto de la corriente italiana—, estrenado a su beneficio en agosto, y para el que creó cuatro decorados nuevos: un bosque habitado por los sátiros; una selva monstruosa consagrada a Diana; un sitio de recreo para los amores; y regia (sic) de Venus en la isla de Chipre $^{97}$. Fue precisamente este último el que agradó más. Al final del ballet, y como

\footnotetext{
90 "Folletín. Revista de la Semana", La Opinión, 29-XI-1846.

91 "Gacetilla de Madrid", El Tiempo, 17-XI-1846.

92 "Revista de Teatros. Circo", El Heraldo, 27-VI-1847.

93 "Revista de Teatros. Circo", El Heraldo, 27-VI-1847.

${ }^{44}$ Vélaz de Medrano: "Revista coreográfico musical. Teatro del Circo: El Corsario", El Español, 25-VI-1847.

95 Fernández de los Ríos: "Revista mensual”, El Siglo Pintoresco, junio 1847.

96 "Gacetilla de la Capital", El Heraldo, 6-VII-1847.

97 "Crónica de Madrid”, La Carta, 23-VIII-1847.
} 


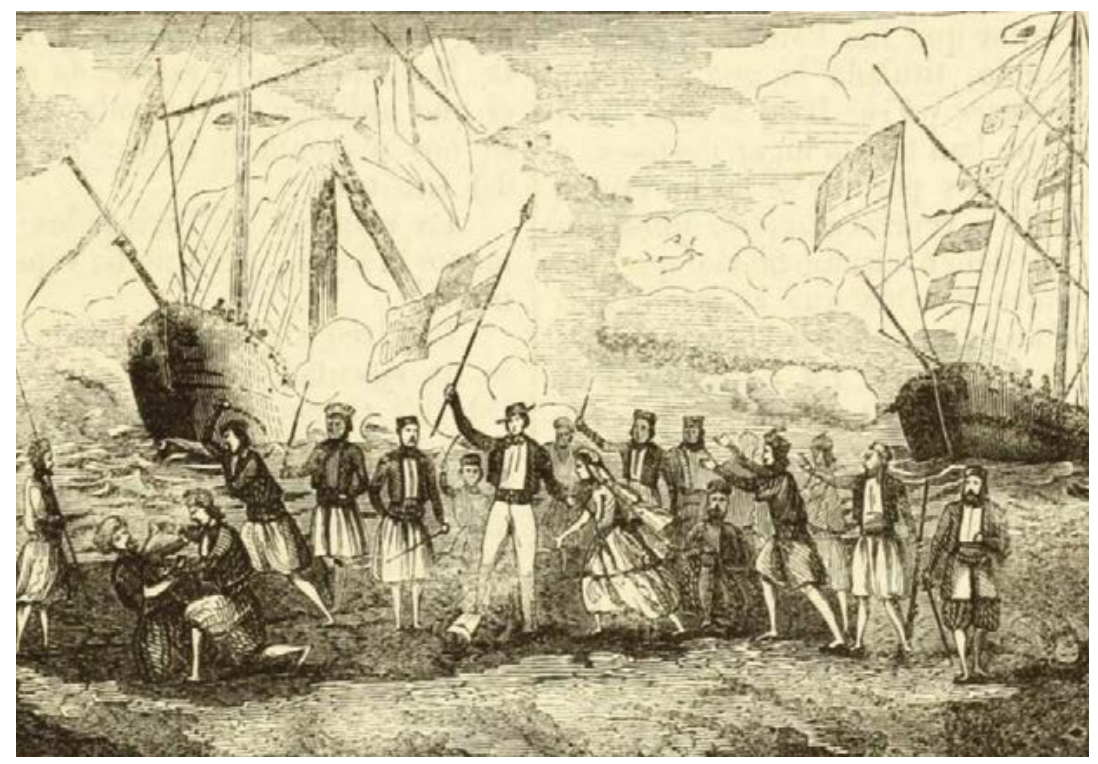

Fig. 5. Última escena de $E l$ Corsario escenificado en Madrid con escenografía de Lucini. (El Siglo Pintoresco, septiembre, 1847).

en otras ocasiones, el escenógrafo salió al escenario para recibir la "justa recompensa por su trabajo artístico"98. Más críticos se mostraron en otro periódico, que consideró que "las decoraciones, aunque bastante buenas, no son sin embargo lo que se esperaba del mágico pincel del Sr. Lucini" ${ }^{99}$.

Para Fausto - ballet en tres actos de Lefebvre cuya recepción fue un gran fracaso- Lucini preparó cinco decorados nuevos: un gabinete de alquimista; un sitio salvaje habitado por espíritus malignos; extremidad (sic) de una aldea; feria en una plaza y apoteosis ${ }^{100}$. En esta ocasión su trabajo no fue tan bien recibido y Fernández de los Ríos dijo que los decorados no ofrecían novedad ni atractivo ${ }^{101}$. Otro cronista también reconoció que, en este ballet, el escenógrafo no había estado tan acertado como en otras producciones, y que solo gustó el último decorado porque "los demás, nada tienen de particular" 102 .

El último ballet en el que trabajó Lucini en 1847 fue El torero, otro fiasco de Lefebvre para el que solo realizó un decorado nuevo. Se trataba de un ballet de medio carácter en dos actos con argumento y bailes españoles, que no fue bien acogido ni por el público ni por la crítica, porque fue considerado casi como una ofensa a los bailarines, bailes y costumbres españolas.

Desde comienzos de 1848, los encargados de escenificar los nuevos ballets en el Teatro del Circo fueron dos primeros bailarines de la compañía: Marie Guy-Stéphan y Pierre Massot. Lucini se encargó de pintar la escenografía de La Sonámbula ${ }^{103}$, ballet prerromántico en tres actos llevado a escena y protagonizado por ambos. Tras el estreno se comentó que esta coreografía valía "mucho más que las insípidas farsas que nos ha dado antes el buen Mr. Lefebre (sic)"104. Sin embargo, se consideró que el éxito del ballet había "sido brillantísimo en apariencia, aun cuando por su mérito no lo creemos de ningún modo merecedor de los estrepitosos aplausos con que fuere recibido" 105 . Parece que, en este ballet, lo que acaparó verdaderamente la atención del público y de la prensa fue el ansiado regreso escénico de Guy-Stephan, que había sido madre de un niño en octubre del año anterior.

98 "Gacetilla de la Corte”, El Español, 22-VIII-1847.

99 "Crónica de Madrid", La Carta, 23-VIII-1847.

100 "Diversiones Públicas. Teatros. Del Circo", Diario de Avisos de Madrid, 18-X-1847.

101 Fernández de los Ríos: "Revista mensual", El Siglo Pintoresco, octubre 1847.

102 "El Fausto", El Clamor Público, 22-X-1847.

103 La somnambule, ou L'arrivée d'un nouveau seigneur, ballet-pantomima coreografiado por Jean Aumer y con música de Ferdinand Herold, estrenado en París en 1827.

104 "Crónica de Teatros", El Clamor Público, 27-I-1848.

105 “Crónica de Madrid”, La Carta, 24-I-1848. 
Posteriormente Lucini se ocupó de otro ballet en tres actos, El diablo a cuatro ${ }^{106}$, cuya escenografía fue toda nueva. Se destacó su mérito en el manejo de la perspectiva y llamó la atención la riqueza de tintas y el gusto en la selección de los adornos para la habitación de la condesa del segundo acto. El efecto más novedoso se presentó en el jardín del tercer acto donde aparecía "un merendero en el que, por efecto de la luz y las telas, el señor Lucini ha fingido cristales hasta un punto increíble"107.

Durante el carnaval de ese año - y debido a su puesto como escenógrafo y jefe de maquinaria del Teatro del Circo-, se le encargó decorar y preparar los accesorios del salón principal del teatro para los seis bailes de máscaras que se iban a ofrecer allí. Además de un telón nuevo, más de treinta arañas y multitud de espejos, la decoración consistió en unir el escenario con la sala y diseñar "una lujosa tribuna en el centro, donde se colocará la brillante orquesta del teatro. Todos los palcos estarán colgados ${ }^{108}$, la alfombra será elegantísima" y se trajo desde París. Con todo ello, Lucini se propuso "dar nueva prueba de su habilidad y buen gusto"109.

\section{Creaciones de Eusebio Lucini en Madrid después de su contrato en Barcelona}

A lo largo de 1849 Lucini trabajó en el Teatro del Liceo de Barcelona y, en 1850, cuando regresó al Teatro del Circo — denominado ahora Teatro de la Ópera ${ }^{110}$ - , se encargó de la escenografía de La corte de Luis XIV $V^{111}$, ballet dramático en cuatro actos puesto en escena por Antonio Appiani. El decorado del último acto reproducía un salón de Versalles iluminado por luces de gas y su imagen "no pudo ser más encantadora", por lo que "agradó sobremanera por su sorprendente efecto" ${ }^{112}$. Un cronista lo describió así:

Un gran salón formado por altísimas columnas a un lado y a otro del escenario, tiene en el fondo una escalinata que se parte en dos ramales de medio punto, que van a terminar en una elegante galería formada por arcos, todos practicables en el hueco de la escalinata, y con un gran efecto. (...) Las columnas están vestidas con centenares de luces en graciosas espirales; la balaustrada de la escalera, las cornisas y todas las molduras, están cubiertas también de vivísimas luces, que dan un aspecto verdaderamente mágico al salón ${ }^{113}$.

En julio de 1850 se encargó de los decorados de Isaura, ahijada de las hadas ${ }^{114}$, ballet en tres actos y un prólogo estrenado a beneficio de Lucini. Se reconoció el "fantástico pincel" del escenógrafo y se señaló que "sus esfuerzos y actividad fueron apreciados como se merecían por el público" 115 después de "haber trabajado tanto para hacer más brillante el éxito del nuevo ballet"116. Se destacó especialmente un telón de la última escena - considerado "sorprendente"-, en el que un grupo encabezado por Isaura avanzaba "entre una lluvia vistosísima de chispas de fuego de diversos colores"117. Este decorado estaba iluminado con luces de bengalas y no

106 Le diable à quatre, coreografía de Mazilier con música de Adam, estrenado en París en 1845. Fue puesto en escena en Madrid por Massot. El diablo a cuatro. Madrid, 1848. BNE, T/12403.

107 "Variedades. Teatro del Circo", El Popular, 9-III-1848.

108 Se refiere a que en los palcos se colgarían telas, cortinas o algún tipo de elemento decorativo.

109 "Miscelánea", Diario de Avisos de Madrid, 8-I-1848.

110 El Decreto orgánico de gobernación de los teatros del reino de 1849, modificó el repertorio y el nombre de los teatros de Madrid.

111 Basado en Un bal sous Luis XIV, divertimento de Perrot con música compuesta y arreglada por Gustave Nadaud, estrenado en Londres en 1843.

112 "Crónica de Teatros", El Clamor Público, 26-V-1850.

113 "Noticias Generales", La Época, 28-V-1850.

114 La filleule des fées, ballet de Perrot con música de Adam, estrenado en París en 1849.

115 "Noticias Generales", La Época, 12-VII-1850.

116 “Gacetilla. Teatro de la Ópera”, La España, 12-VII-1850.

117 “Gacetilla de la capital”, El Heraldo, 11-VII-1850. 
podía "compararse con nada de lo que se ha hecho hasta el día"118. Por todo ello, Lucini fue llamado a la escena para ser aplaudido con entusiasmo por los espectadores.

Después de este ballet, Eusebio Lucini no creó más escenografías para el Teatro del Circo y pasó a integrarse en el personal artístico del Teatro Real desde su inauguración.

Escenografías de ballets y óperas creadas por Eusebio Lucini en el Teatro del Circo de Madrid entre 1842-1850119

\begin{tabular}{|c|c|c|c|}
\hline Título & $\begin{array}{l}\text { Número de decorados } \\
\text { realizados }\end{array}$ & $\begin{array}{l}\text { Coreógrafo/ } \\
\text { Compositor }\end{array}$ & Fecha \\
\hline La Vestale & Todos & Mercadante & 1842 \\
\hline Lucrecia Borgia & $1^{120}$ & Donizetti & 1842 \\
\hline César en Egipto & 5 de $6^{121}$ & Massini & 1842 \\
\hline Saffo & 1 & Gio Pacini & 1842 \\
\hline La viuda caprichosa & 1 & Massini & 1842 \\
\hline La Silfide & Todos (4) & Massini & 1842 \\
\hline I Giuramento & $2^{122}$ de 3 & Mercadante & 1842 \\
\hline Los griegos o la libertad de Grecia & Todos & Rouquet & 1843 \\
\hline Los Titanes o las cuatro edades del mundo & Todos $(8)$ & Massini & 1843 \\
\hline La Gypsy & Todos (5) & Henry & 1843 \\
\hline Gisela o las willis & Todos & Henry & 1843 \\
\hline La Aurora & 1 & Henry & 1843 \\
\hline El lago de las hadas & 3 & Villa & 1843 \\
\hline Los ingleses en el Indostán & Todos (5) & Villa & 1844 \\
\hline La isla del amor & Todos & Villa & 1844 \\
\hline L'Esule di Roma & $2^{123}$ & Donizetti & 1844 \\
\hline La hermosa Beatriz & 5 de 7 & JBarrez & 1844 \\
\hline La tarántula & 2 & Barrez & 1844 \\
\hline La Péri & Todos & Barrez & 1844 \\
\hline El diablo enamorado & Todos (6) & Barrez & 1845 \\
\hline I Martirit $^{124}$ & Todos & Donizetti & 1845 \\
\hline I due foscari ${ }^{125}$ & Todos & Verdi & 1845 \\
\hline La Ondina & Todos (4) & Petipa & 1845 \\
\hline
\end{tabular}

118 "Boletín de espectáculos. Teatro de la Ópera", La Nación, 11-VII-1850.

119 Tabla elaborada por la autora.

${ }^{120}$ Cuando se repuso esta ópera, en octubre de 1845 , se estrenó otro decorado realizado por Lucini. "Diversiones Públicas. Teatros. Circo", Diario de Avisos de Madrid, 14-X-1845.

121 En colaboración con Pedro Ronzi.

122 Pedro Ronzi realizó otro decorado para el $1{ }^{\text {er }}$ acto.

123 Considerados "de extraordinario mérito", "L'Esule di Roma", La Posdata, 18-VI-1844.

124 A beneficio de Lucini. Sus decorados estuvieron "perfectamente entendidos, mejor desempeñados y con efectos admirables", La Posdata, 22-II-1845. "El aparato escénico, la magnificencia de las decoraciones y su propiedad, especialmente la del último acto que representa un circo romano (...), exceden a todo elogio", "Sección Literaria. Teatro del Circo", El Clamor Público, 23-II-1845.

${ }^{125}$ Los nuevos decorados eran "magníficos, haciéndose notar por su belleza el que representa al senado", "Revista de Teatros", Revista de Teatros, 25-VII-1845. 


\begin{tabular}{|l|c|c|c|}
\hline \multicolumn{1}{|c|}{ Título } & $\begin{array}{c}\text { Número de decorados } \\
\text { realizados }\end{array}$ & $\begin{array}{c}\text { Coreógrafo/ } \\
\text { Compositor }\end{array}$ & Fecha \\
\hline La Esmeralda & Todos & Petipa & 1845 \\
\hline Farfarella o la hija del infierno & Todos (6) & Petipa & 1846 \\
\hline Giovanna de Arco ${ }^{126}$ & 1 & Verdi & 1846 \\
\hline La Fortuna o la reina del mundo & Todos (7) & Massot & 1846 \\
\hline La mutta di Portice & 1 & Auber & 1847 \\
\hline Medea in Corinto & 2 & Pacini & 1847 \\
\hline Alba Flor la pesarosa & ¿Todos? & Petipa & 1847 \\
\hline El Corsario & Todos & Lefebvre & 1847 \\
\hline Cloris en la corte de Diana & 4 & Lefebvre & 1847 \\
\hline Fausto & 5 & Lefebvre & 1847 \\
\hline El torero & 1 & Lefebvre & 1847 \\
\hline La gazza ladra & 2 & Rossini & 1848 \\
\hline La sonámbula & $¿ ?$ & Massot y Guy & 1848 \\
\hline Macbeth ${ }^{127}$ & Todos (7) & Verdi & 1848 \\
\hline El diablo a cuatro & Todos & Massot y Guy & 1848 \\
\hline La corte de Luis XIV & Todos & Appiani & 1850 \\
\hline Isaura, ahijada de las hadas ${ }^{128}$ & Todos & Appiani & 1850 \\
\hline
\end{tabular}

\section{A modo de conclusión}

A pesar de que, durante el siglo XIX, la "pintura de escena" fue la parte de la producción a la que con frecuencia se destinó menos presupuesto y, por tanto, la reutilización y adaptación de decorados procedentes de otros espectáculos fue una tónica en los teatros de Europa, Eusebio Lucini desempeñó una labor fundamental como escenógrafo y director de maquinaria del Teatro del Circo durante varios años, en los que realizó escenografías para cuarenta espectáculos representados en dicho coliseo: doce óperas y veintiocho ballets. De ellos, diseñó todos los decorados para cuatro óperas y diecisiete ballets.

Mientras que los ballets escenificados en el Teatro del Circo de Madrid sufrieron alteraciones importantes en el argumento, en las danzas y en la música, desde el punto de vista escenográfico, las producciones madrileñas mantuvieron bastantes semejanzas con las indicaciones de escenografía previstas en los montajes originales, aunque, para algunos críticos, en algunos casos su ejecución podría haber sido mejorable. Se puede llegar a esta conclusión comparando las indicaciones de los libretos originales con los de Madrid, donde se observa que existieron pocas variaciones. Quizás las diferencias más notables, desde el punto de vista de los decorados, estuvieron motivadas por dos aspectos:

En primer lugar, por la necesidad de economizar gastos — que obligó, por ejemplo, a suprimir la construcción de una fuente en La Ondina, o a no desarrollar una escena a la orilla del Sena en La Esmeralda - . No obstante, hemos visto testimonios que reflejan el importante gasto económico realizado por José de Salamanca, durante la etapa que fue empresario del teatro, para costear las producciones al más alto nivel.

126 Creó la vista de una plaza, considerada como "otro nuevo y bonito decorado", "Revista Musical. Teatro del Circo. Giovanna d'Arco ópera de Verdi”, El Español, 10-XI-1846.

${ }^{127}$ A beneficio de Lucini.

128 A beneficio de Lucini. 
En segundo lugar, por las dimensiones del propio escenario ya que, el del Teatro del Circo, por sus peculiaridades arquitectónicas, era más pequeño que el de la Ópera parisina o el del Teatro Real londinense. Esto implicó, por ejemplo, que el estudio del pintor de Farfarella o el espléndido salón de baile de La corte de Luis XIV fueran de menor tamaño, pero no por ello de peor factura que los europeos.

Eusebio Lucini - cuya actividad artística continuó en el Teatro Real tras su inauguración en noviembre de 1850 - logró convertirse en uno de los pintores escénicos más activos y destacados de la España isabelina ${ }^{129}$ y formó parte de un grupo de escenógrafos italianos entre los que predominaba el uso del cartón piedra, que utilizaban para mostrar el lujo y la grandiosidad. A pesar de la escasa información conservada, Navascués se aventuró a considerar que sus escenografías "revelan un gusto inequívocamente italiano en la línea rígida de Alessandro Sanquirico, uno de los más sobresalientes escenógrafos de la Scala de Milán, cuya obra debió conocer personalmente Lucini"'130. Sin embargo, hemos podido comprobar cómo Lucini también destacó a la hora de dibujar y pintar telones.

Lamentablemente, de su trabajo como escenógrafo no ha sobrevivido nada, a excepción de pequeños grabados publicados en la prensa, lo que nos impide acceder a las fuentes primarias para realizar un análisis más completo. Lo poco que conocemos de sus escenografías es gracias a las descripciones y opiniones publicadas en la prensa de la época - siempre tomadas con cautela, porque no están exentas de subjetivismos, filias y fobias. Además de utilizar con frecuencia frases comodín como "nunca antes visto en nuestros teatros", entre otras expresiones también aplicadas a los bailarines - y breves comentarios en estudios posteriores. A pesar de ello, estos obstáculos no deberían justificar que el trabajo de Lucini siga permaneciendo en las sombras.

Este recorrido por la todavía poco estudiada producción escenográfica para ballet de Eusebio Lucini, desarrollada durante la década de 1840, pretende visibilizar y poner en valor su gran actividad artística además de constatar que, en el Teatro del Circo de Madrid, existió entonces una programación equivalente a la de los teatros más importantes de Europa, también en cuanto a los diseños escenográficos.

\section{BIBLIOGRAFÍA}

Arias de Cossío, Ana Ma (1991): Dos siglos de escenografia en Madrid. Madrid: Mondadori.

Arregui, Jon (2009): Los arbitrios de la ilusión: los teatros del siglo XIX. Madrid: ADE.

Di Tondo, Ornella (2012): "The Italian sílfide and the contentious reception of Ultramontane ballet". En: La Sylphide 1832 and beyond. Londres: Dance Books.

Girardi, Michele/ Rossi, Franco (1989): Il Teatro La Fenice Cronologia degli spettacoli (1792-1936). Venecia: Albrizzi. Hormigón, Laura (2010): Marius Petipa en España (1844-1847). Memorias y otros materiales. Madrid: Danzarte Ballet. Hormigón, Laura (2017): El Ballet Romántico en el Teatro del Circo de Madrid (1842-1850). Madrid: Asociación de Directores de Escena de España.

Hormigón, Laura (2018): "La apasionante fuga de España de Marius Petipa. Una cuestión de Estado". En: ADE-Teatro (169), 8-19. Madrid: ADE.

Manjarrés, José de (1875): El arte en el teatro. Barcelona: Librería Bastinos.

Moynet, M. Jules (1999): El teatro del siglo XIX por dentro. Madrid: ADE.

Muñoz Morillejo, Joaquín (1923): Escenografia española. Madrid: Real Academia de San Fernando.

Navascués, Pedro (1984): "Las máquinas teatrales: Arquitectura y escenografía”. En: Arquitectura teatral en España. Madrid: Ministerio de Obras Públicas y Urbanismo.

Nieva, Francisco (2000). Tratado de escenografia. Madrid: Fundamentos.

Smith, Marian (2000): Ballet and opera in the age of Giselle. New Jersey: Princeton University Press.

Fecha de recepción: 3-IV-2020

Fecha de aceptación: 15-VII-2020

\footnotetext{
129 Navascués, 1984.
}

130 Navascués, 1984. 